\title{
Article \\ The Impact of Restricted versus Liberal Early Fluid Volumes on Plasma Sodium, Weight Change, and Short-Term Outcomes in Extremely Preterm Infants
}

\author{
Barbro Diderholm *(D), Erik Normann, Fredrik Ahlsson (D), Richard Sindelar (D) and Johan Ågren (D) \\ Department of Women's and Children's Health, Uppsala University Children's Hospital, \\ SE-75185 Uppsala, Sweden; erik.normann@kbh.uu.se (E.N.); fredrik.ahlsson@kbh.uu.se (F.A.); \\ richard.sindelar@kbh.uu.se (R.S.); johan.agren@kbh.uu.se (J.Å.) \\ * Correspondence: barbro.diderholm@kbh.uu.se; Tel.: +46-186119647
}

check for updates

Citation: Diderholm, B.; Normann, E.; Ahlsson, F.; Sindelar, R.; Ågren, J. The Impact of Restricted versus Liberal Early Fluid Volumes on Plasma Sodium, Weight Change, and Short-Term Outcomes in Extremely Preterm Infants. Nutrients 2022, 14, 795. https://doi.org/10.3390/ nu14040795

Academic Editor: Roberto Iacone

Received: 7 January 2022

Accepted: 9 February 2022

Published: 14 February 2022

Publisher's Note: MDPI stays neutral with regard to jurisdictional claims in published maps and institutional affiliations.

Copyright: (c) 2022 by the authors. Licensee MDPI, Basel, Switzerland. This article is an open access article distributed under the terms and conditions of the Creative Commons Attribution (CC BY) license (https:// creativecommons.org/licenses/by/ $4.0 /)$.
Abstract: The optimal fluid requirements for extremely preterm infants are not fully known. We examined retrospectively the fluid intakes during the first week of life in two cohorts of extremely preterm infants born at 22-26 weeks of gestation before $(n=63)$ and after a change from a restrictive to a more liberal $(n=112)$ fluid volume allowance to improve nutrient provision. The cohorts were similar in gestational age and birth weight, but antenatal steroid exposure was more frequent in the second era. Although fluid management resulted in a cumulative difference in the total fluid intake over the first week of $87 \mathrm{~mL} / \mathrm{kg}(p<0.001)$, this was not reflected in a mean weight loss (14 $\pm 5 \%$ at a postnatal age of 4 days in both groups) or mean peak plasma sodium (142 \pm 5 and $143 \pm 5 \mathrm{mmol} / \mathrm{L}$ in the restrictive and liberal groups, respectively). The incidences of hypernatremia (>145 and >150 mmol/L), PDA ligation, bronchopulmonary dysplasia, and IVH were also similar. We conclude that in this cohort of extremely preterm infants a more liberal vs. a restricted fluid allowance during the first week had no clinically important influence on early changes in body weight, sodium homeostasis, or hospital morbidities.

Keywords: extremely preterm infant; fluid allowance; dehydration

\section{Introduction}

The evidence base to guide initial fluid management for extremely preterm infants is limited. A few randomized controlled trials [1-5] have studied the impact of different levels of either sodium, water, or both sodium and water provision, on survival and the risk of cardiorespiratory morbidity. The regimes applied in these investigations were different, but in those where sodium intake was varied separately from water a restricted sodium intake resulted in a lower rate of bronchopulmonary dysplasia (BPD) and a lower mortality. Based on these studies the most current recommendations [6] suggest an initial restriction of both water and sodium intake, presumably since in most instances an increased total fluid volume will also infer an increased amount of sodium provided. Importantly, these studies include a limited number of infants with a gestational age (GA) below 28 weeks and might thus not provide much guidance to the care provided to this subpopulation. The aim of the present investigation was to study the effects of an implemented change in the initial fluid volume provision on early measures of hydration and hospital outcomes in a cohort of extremely preterm infants. The change to higher starting fluid volumes was initiated with the ambition to improve energy and nutrient provision and was not primarily driven by perceived difficulties with excessive weight loss and/or electrolyte imbalances. 


\section{Materials and Methods}

The investigation evaluated an implemented increase in the total starting fluid volume allowance to extremely preterm infants at a tertiary care neonatal intensive care unit (Uppsala University Children's Hospital).

\subsection{Subjects}

Data were retrospectively collected from all in-born $(n=204)$ extremely preterm infants with a gestational age (GA) of 22-26 weeks, during a 6-year period (2002-2007). By design this included a 3-year period of lower fluid volumes (RESTRICTED) before the change in fluid allowance, and a 3-year period after the implementation of the higher fluid volume allowance (LIBERAL). Infants who died or were transferred to other units within the 1st week were excluded, leaving a total of 175 infants for further analysis (RESTRICTED $n=63$; LIBERAL $n=112$ ) with a mean GA of $25^{1 / 7}$ (range $22^{1 / 7}-26^{6 / 7}$ ) weeks (Figure 1$)$.

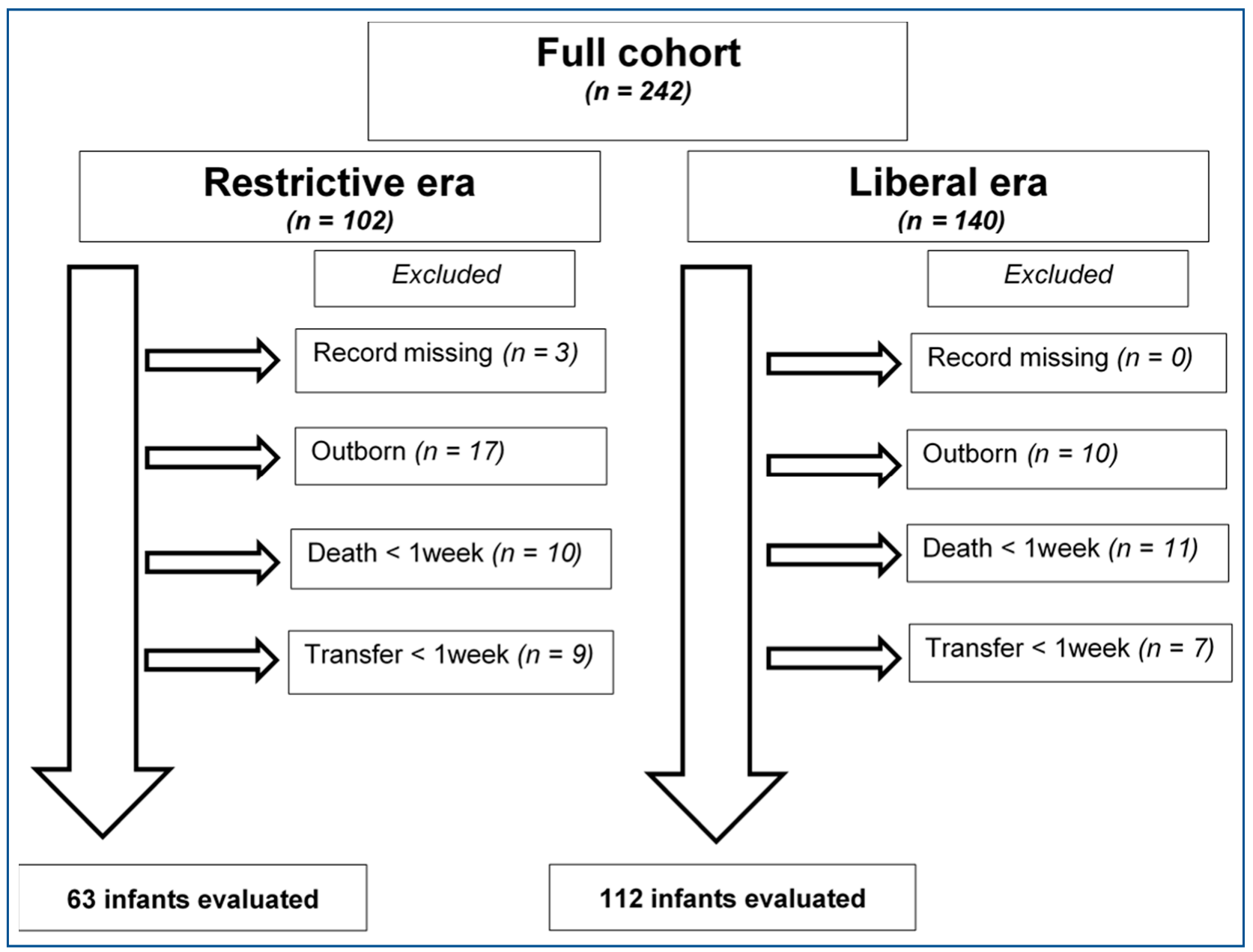

Figure 1. Included and excluded infants in the study cohort.

The groups were similar in GA and birth weight (Table 1). The administration of antenatal steroids $<24 \mathrm{~h}$ prior to delivery was more frequent in the later (LIBERAL) era $(p<0.05$, Table 1). Including all infants admitted, survival to discharge was $77 / 102(75 \%)$ and 119/140 (85\%) in RESTRICTED and LIBERAL eras, respectively $(p=0.0696)$. 
Table 1. Study cohort.

\begin{tabular}{cccc}
\hline & RESTRICTED $(\boldsymbol{n}=\mathbf{6 3})$ & LIBERAL $(\boldsymbol{n = 1 1 2})$ & $\boldsymbol{p}^{\text {a }}$ \\
\hline Gestational age (weeks) & $25.2 \pm 1.2$ & $25.1 \pm 1.1$ & n.s. ${ }^{\text {a }}$ \\
Birthweight (g) & $744 \pm 192$ & $718 \pm 156$ & n.s. ${ }^{\text {a }}$ \\
Antenatal steroids & $50(79)$ & $103(92)$ & $<0.05^{\text {b }}$ \\
Surfactant & $57(90)$ & $107(96)$ & n.s. ${ }^{\text {b }}$ \\
\hline
\end{tabular}

Values are mean $\pm \mathrm{SD}$, or $n(\%)$. ${ }^{\text {a }}$ Unpaired $t$-test, ${ }^{\mathrm{b}}$ Fisher's exact test.

\subsection{Study Setting}

All infants were cared for in closed intensive care incubators set at a high relative humidity of $85 \%$ during the first week, after which a setting of $50 \%$ was used. In brief, the institutional fluid prescription guidelines specified a starting total fluid volume and a standard flush solution $(\mathrm{NaCl} 9 \mathrm{mg} / \mathrm{mL}$ at $0.5 \mathrm{~mL} / \mathrm{h}$ ) for umbilical arterial lines. Enteral feeds (donor breast milk, later replaced with Mom's own) were to be started within $2 \mathrm{~h}$ with a volume of approximately $20 \mathrm{~mL} / \mathrm{kg} / \mathrm{d}$ and with a recommended increase of approximately $20 \mathrm{~mL} / \mathrm{kg} / \mathrm{d}$ until full feeds $(170 \mathrm{~mL} / \mathrm{kg} / \mathrm{d}$ ) were reached. Parenteral nutrition (PN; amino acids, glucose, and lipids) were also started at birth. Supplementation of sodium was not to be provided until weight loss and a drop in serum sodium had occurred. In the RESTRICTED group an initial total fluid volume of $65 \mathrm{~mL} / \mathrm{kg} /$ day was recommended with a scheduled daily stepwise increase of $10 \mathrm{~mL} / \mathrm{kg} /$ day up to $170 \mathrm{~mL} / \mathrm{kg} /$ day. In the LIBERAL group total fluids were started at $95 \mathrm{~mL} / \mathrm{kg} /$ day (GA 22-24 weeks) and $85 \mathrm{~mL} / \mathrm{kg} / \mathrm{d}$ (GA 25-26 weeks), respectively. In the LIBERAL era the recommended daily increase in fluid volume allowance was also $10 \mathrm{~mL} / \mathrm{kg} / \mathrm{d}$ to be adjusted at the discretion of the attending neonatologist, depending on changes in body weight (determined daily), urinary output, blood biochemistry values (determined q $6 \mathrm{~h}$ until stable), and clinical status. The LIBERAL era guidelines advocated for fluid management also to be guided mainly by the serial determinations of body weight to allow a weight loss of up to $3-4 \%$ per day and a total maximum weight loss of $10-15 \%$. During the study period a subset of infants $(n=41)$ born after October 2005 received an amino acid flush solution in their umbilical artery catheter [7], but no other changes were made in the guidelines for enteral or parenteral nutrition or for transfusions.

\subsection{Data Collection and Treatment}

Data were collected from the patients' records and fluid charts and included details on all fluids provided (volume and route of administration), transfusion volumes, postnatal changes in body weight, and blood biochemistry values. Hypernatremia was categorized as moderate $(\mathrm{P}-\mathrm{Na}>145 \mathrm{mmol} / \mathrm{L})$ or severe $(\mathrm{P}-\mathrm{Na}>150 \mathrm{mmol} / \mathrm{L})$, and hyponatremia was defined as a P-Na of $<130 \mathrm{mmol} / \mathrm{L}$. Further, data on selected short-term outcomes considered relevant to early fluid provision were collected; including the incidence of intraventricular hemorrhage (IVH), surgical ligation of persistent ductus arteriosus (PDA), and bronchopulmonary dysplasia (BPD) (defined as oxygen dependency at 36 weeks postmenstrual age).

The values are presented as mean $\pm \mathrm{SD}$ or median (range), the Student's $t$-test on unpaired observations and the Fisher's exact test were used to test for statistical significance, and $p<0.05$ was considered statistically significant.

\section{Results}

The starting fluid volume intake was $19 \mathrm{~mL} / \mathrm{kg} / \mathrm{d}$ higher $(p<0.001)$ in LIBERAL vs. RESTRICTED (Table 2 ) and subsequently resulted in an accumulated fluid volume excess of $87 \mathrm{~mL} / \mathrm{kg}$ for the 1 st week $(p<0.001$, Table 2$)$. 
Table 2. Fluid volumes, weight change, and plasma sodium.

\begin{tabular}{|c|c|c|c|c|}
\hline & & RESTRICTED & LIBERAL & \\
\hline & & $(n=63)$ & $(n=112)$ & $p^{\mathrm{a}}$ \\
\hline Total fluids & (mL/kg/day) & & & \\
\hline DOL 1 & & $72 \pm 12$ & $91 \pm 15$ & $<0.001$ \\
\hline DOL 4 & & $110 \pm 14$ & $118 \pm 14$ & $<0.001$ \\
\hline DOL 8 & & $143 \pm 20$ & $150 \pm 19$ & 0.056 \\
\hline DOL 11 & & $168 \pm 15$ & $171 \pm 14$ & n.s. \\
\hline \multicolumn{5}{|l|}{ 1st week } \\
\hline Total fluids & (mL/kg/day) & $111 \pm 11$ & $122 \pm 12$ & $<0.001$ \\
\hline Transfusion volume & $(\mathrm{mL} / \mathrm{kg})$ & $15 \pm 16$ & $16 \pm 14$ & n.s. \\
\hline Ratio EN:PN & & $1: 1.7$ & $1: 2.1$ & n.s. \\
\hline \multicolumn{5}{|l|}{ Weight change } \\
\hline Nadir & $(\%)$ & $-14 \pm 5$ & $-14 \pm 5$ & n.s. \\
\hline Age at nadir & (days) & $5(1-7)$ & $4(2-7)$ & n.s. \\
\hline DOL 8 & $(\%)$ & $-9 \pm 7$ & $-10 \pm 6$ & n.s. \\
\hline DOL 28 & $(\%)$ & $+29 \pm 15$ & $+29 \pm 12$ & n.s. \\
\hline \multicolumn{5}{|l|}{ Plasma sodium } \\
\hline Peak & $(\mathrm{mmol} / \mathrm{L})$ & $142 \pm 5$ & $143 \pm 5$ & n.s. \\
\hline Age at peak & (days) & $3(1-7)$ & $3(1-7)$ & n.s. \\
\hline $\begin{array}{c}\text { Sodium } \\
\text { supplementation }\end{array}$ & $(\%)$ & $50(80)$ & $90(80)$ & n.s. \\
\hline Age at start & (days) & $7(2-17)$ & $7(3-13)$ & n.s. \\
\hline
\end{tabular}

Values are mean \pm SD, median (range), or $n(\%)$. DOL—Day of life; EN: PN—Enteral: Parenteral nutrition, a Unpaired $t$-test.

No differences were found in the accumulated volume of transfusions or in the feeding strategy, as demonstrated by the ratio of enteral vs. parenteral nutrition in the groups (Table 2). Thus, the higher total fluids in LIBERAL consisted of higher volumes of parenteral nutrition. Irrespective of the distinct differences in fluid provision, the two groups displayed a similar peak in plasma sodium concentration at a postnatal age of 3 days (Table 2). The trajectories of P-Na are displayed in Figure 2.

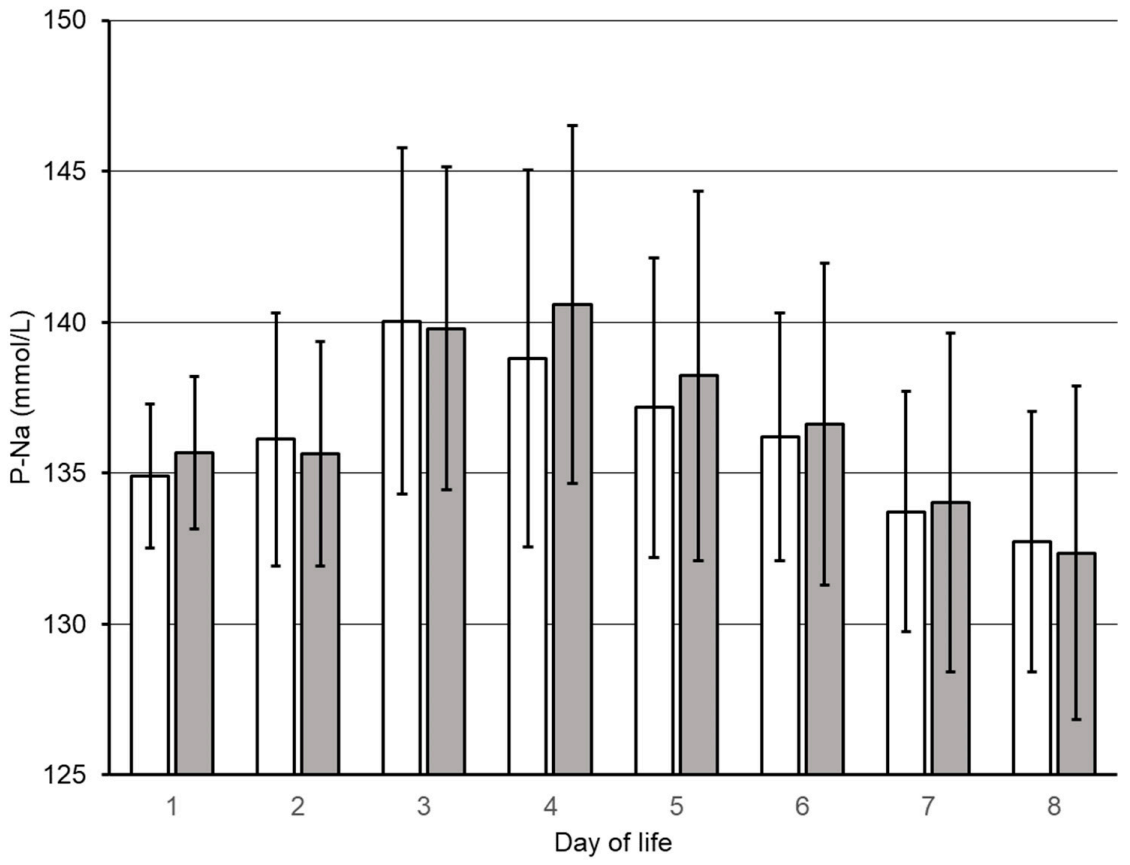

Figure 2. Trajectories of first week plasma sodium (P-Na) concentrations. RESTRICTED group, open bars; LIBERAL group, filled bars; Mean \pm SD. 
Most interestingly, the groups were also similar and parallel in their postnatal changes in body weight (Figure 3), including a nadir at a postnatal age of 4-5 days (Table 2). Further, there were no differences between the two groups in the incidence of hyperand hyponatremia (Table 3) and the groups had a similar incidence of IVH, PDA, and BPD (Table 3).

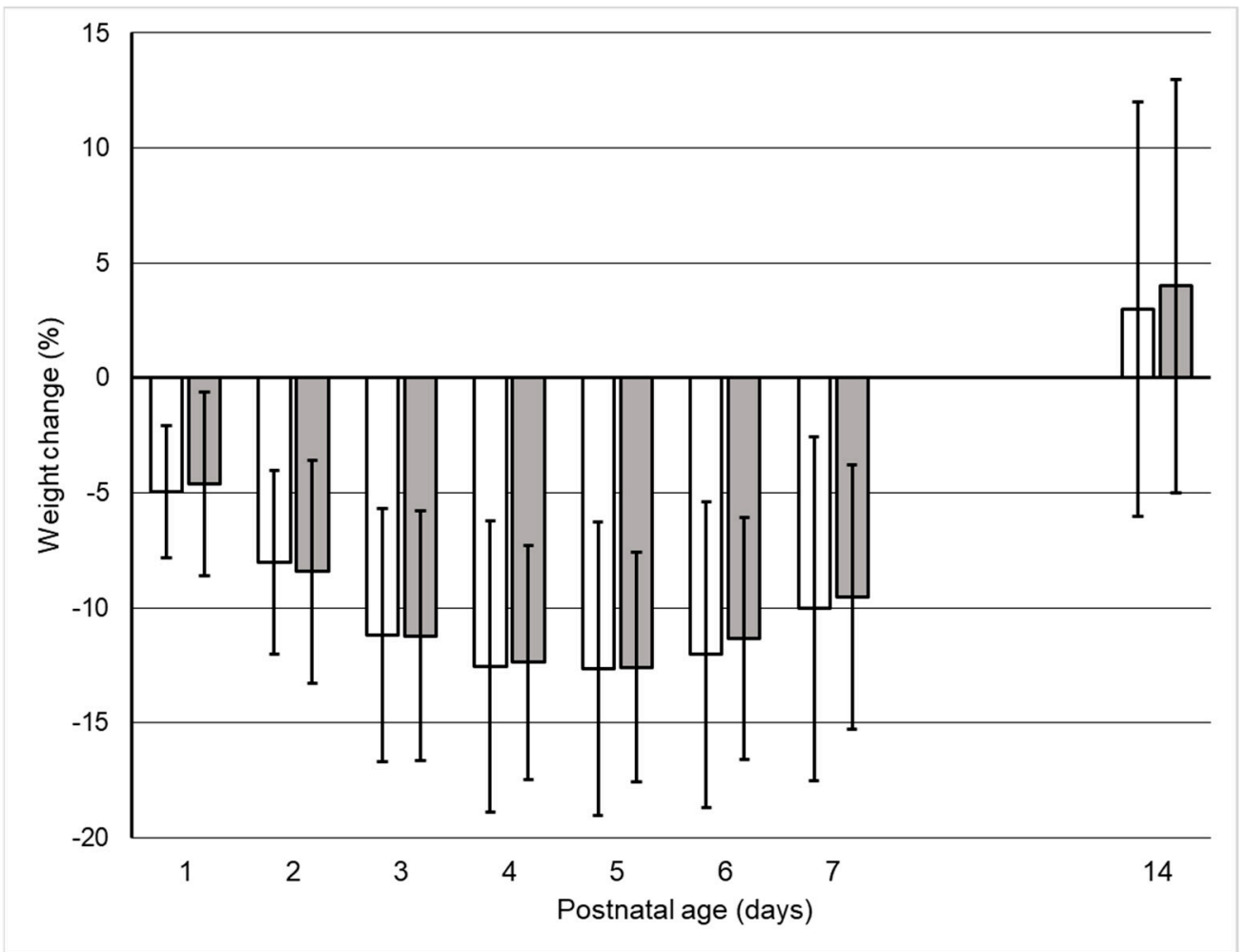

Figure 3. Relative changes in body weight. RESTRICTED group, open bars; LIBERAL group, filled bars; Mean \pm SD.

Table 3. Plasma sodium during 1st week and related morbidities.

\begin{tabular}{cccc}
\hline & RESTRICTED & LIBERAL & \\
\hline & $(\boldsymbol{n}=\mathbf{6 3})$ & $(\boldsymbol{n = 1 1 2})$ & $\boldsymbol{p}^{\mathbf{a}}$ \\
\hline Hypernatremia & & & \\
$>145 \mathrm{mmol} / \mathrm{L}$ & $18(29)$ & $40(36)$ & n.s. \\
$>150 \mathrm{mmol} / \mathrm{L}$ & $6(10)$ & $12(11)$ & n.s. \\
Hyponatremia & & & \\
$<130$ mmol/L & $13(21)$ & $24(21)$ & n.s. \\
Hospital morbidity & $24(38)$ & $41(36)$ & n.s. \\
BPD & $20(32)$ & $39(34)$ & n.s. \\
PDA ligation & $16(25)$ & $21(19)$ & n.s. \\
IVH, all grades & $8(14)$ & $8(7)$ & n.s. \\
IVH, grades 3-4 & & &
\end{tabular}

Values are $n(\%)$. BPD—bronchopulmonary dysplasia; PDA—persistent ductus arteriosus; IVH—intraventricular hemorrhage; ${ }^{a}$ Fisher's exact test.

\section{Discussion}

The present investigation presents data from a cohort of two 3-year epochs of extremely preterm (GA 22-26 weeks) infants before and after an implemented change in the total fluid volume allowance during the first week of life. The two different levels of fluid volume provided had no discernible impact on weight loss, plasma sodium ( $\mathrm{P}-\mathrm{Na})$, or the incidence 
of either hyper- or hyponatremia. In addition, there were no significant differences in the incidences of the selected hospital outcomes between the groups.

The results are consistent with several randomized trials with a large variation in design and outcome measures, but which have all included preterm infants [8]. Two previous studies that investigated the effect of two different levels of water intake-while sodium intake was equivalent [3,5] - demonstrated no effect on survival and/or the incidence of BPD, while studies where sodium intake varied $[1,2,4,9]$ seem to favor the restriction of early sodium intake. These investigations are indirectly supported by more recent data obtained from infants below 27 weeks in the Swedish EXPRESS study [10]. This investigation demonstrated that there seems to be little impact of fluid volume per se on $\mathrm{P}-\mathrm{Na}$, while both $\mathrm{P}-\mathrm{Na}$ and the incidence of hypernatremia correlate with the amount of sodium provided. Altogether, these findings support the notion that early sodium provision should be restricted until S-Na drops and weight loss is underway [11,12]. Indeed, extremely preterm infants also seem to have the ability to regulate urinary output and thus to handle an interval of fluid volumes in the maintenance range, even early after birth [13-15].

In parallel with recently presented data from infants born at 22 and 23 weeks at our institution [16], the incidence of hypernatremia is low compared to what has been published from similar populations [10,17-19]. Preliminary data from the EXPRESS cohort supports the notion that this might at least partly be explained by the relatively restrictive transfusion policy applied at our institution (C. Späth et al., manuscript in preparation).

The present investigation is limited by its retrospective nature, and albeit being from a single center with an explicitly guideline-driven fluid management and standardized care environment we cannot exclude that changes in the clinical management over time might have influenced our findings. Regrettably, we do not have access to detailed calculations of sodium intake that might have influenced the findings, and it is conceivable that some infants in the LIBERAL group could have received a higher amount of sodium since the increase in fluids was from parenteral nutrition containing sodium. In addition, the hospital outcomes chosen are at best crude representations of perturbations in fluid balance and/or cardiorespiratory function. Nevertheless, we strongly believe that the cohort and its management to be relevant to the care currently provided to this group of highly vulnerable infants. In this context, it may be reassuring to conclude that there seems to be an interval of fluid volumes that may well support near-optimal fluid homeostasis.

\section{Conclusions}

In a cohort of extremely preterm infants the implementation of a more liberal fluid volume allowance had no influence on early changes in body weight, plasma sodium concentrations, the incidence of hypernatremia, short-term growth, or the occurrence of IVH, PDA ligation, and BPD. As long as early sodium load is limited, the implementation of a higher starting fluid volume allowance to achieve better nutrient/caloric intakes might be a feasible approach.

Author Contributions: Conceptualization, R.S. and J.Å.; methodology, data collection and curation, supervision, J.Å.; formal analysis, B.D., E.N., F.A., R.S. and J.Å.; writing—original draft preparation, B.D., F.A., and J.Å.; writing-review and editing, B.D., E.N., F.A., R.S. and J.Å.; funding acquisition, B.D., F.A., and J.Å. All authors have read and agreed to the published version of the manuscript.

Funding: Financial support was obtained from: Gillbergska stiftelsen, Födelsefonden, and HKH Kronprinsessan Lovisa's fund.

Institutional Review Board Statement: The study was conducted in accordance with the Declaration of Helsinki, and approved by the Uppsala Ethical Review Board (protocol no: 2006/028; 22 February 2006).

Informed Consent Statement: Consent has been waived, since the study is a retrospective chart review.

Data Availability Statement: Raw data supporting the results reported in this publication can be found at: https:/ / www.researchgate.net/profile/Johan-Agren/research (accessed on 8 February 2022). 
Acknowledgments: The authors would like to acknowledge the work of former colleagues Gunnar Sjörs and Uwe Ewald advancing the fluid regime now under study.

Conflicts of Interest: The authors declare no conflict of interest.

\section{References}

1. Costarino, A.T., Jr.; Gruskay, J.A.; Corcoran, L.; Polin, R.A.; Baumgart, S. Sodium restriction versus daily maintenance replacement in very low birth weight premature neonates: A randomized, blind therapeutic trial. J. Pediatr. 1992, 120, 99-106. [CrossRef]

2. Hartnoll, G.; Betremieux, P.; Modi, N. Randomised controlled trial of postnatal sodium supplementation on body composition in 25 to 30 week gestational age infants. Arch. Dis. Child Fetal. Neonatal. Ed. 2000, 82, F24-F28. [CrossRef] [PubMed]

3. Kavvadia, V.; Greenough, A.; Dimitriou, G.; Forsling, M.L. Randomized trial of two levels of fluid input in the perinatal periodeffect on fluid balance, electrolyte and metabolic disturbances in ventilated VLBW infants. Acta Paediatr. 2000, 89, $237-241$. [CrossRef] [PubMed]

4. Tammela, O.K.; Koivisto, M.E. Fluid restriction for preventing bronchopulmonary dysplasia? Reduced fluid intake during the first weeks of life improves the outcome of low-birth-weight infants. Acta Paediatr. 1992, 81, 207-212. [CrossRef] [PubMed]

5. von Stockhausen, H.B.; Struve, M. Effects of highly varying parenteral fluid intakes in premature and newborn infants during the first three days of life (author's transl). Klin. Padiatr. 1980, 192, 539-546. [PubMed]

6. Bell, E.F.; Acarregui, M.J. Restricted versus liberal water intake for preventing morbidity and mortality in preterm infants. Cochrane Database Syst. Rev. 2014, 2014, CD000503. [CrossRef] [PubMed]

7. Gialamas, S.; Stoltz Sjostrom, E.; Diderholm, B.; Domellof, M.; Ahlsson, F. Amino acid infusions in umbilical artery catheters enhance protein administration in infants born at extremely low gestational age. Acta Paediatr. 2021. early view. [CrossRef] [PubMed]

8. Barrington, K.J.; Fortin-Pellerin, E.; Pennaforte, T. Fluid restriction for treatment of preterm infants with chronic lung disease. Cochrane Database Syst. Rev. 2017, 2, CD005389. [CrossRef] [PubMed]

9. Lorenz, J.M.; Kleinman, L.I.; Kotagal, U.R.; Reller, M.D. Water balance in very low-birth-weight infants: Relationship to water and sodium intake and effect on outcome. J. Pediatr. 1982, 101, 423-432. [CrossRef]

10. Spath, C.; Sjostrom, E.S.; Ahlsson, F.; Agren, J.; Domellof, M. Sodium supply influences plasma sodium concentration and the risks of hyper- and hyponatremia in extremely preterm infants. Pediatr. Res. 2017, 81, 455-460. [CrossRef] [PubMed]

11. Barrington, K.J. Management during the first $72 \mathrm{~h}$ of age of the periviable infant: An evidence-based review. Semin. Perinatol. 2014, 38, 17-24. [CrossRef]

12. Hartnoll, G. Basic principles and practical steps in the management of fluid balance in the newborn. Semin. Neonatol. 2003, 8, 307-313. [CrossRef]

13. Jose, P.A.; Fildes, R.D.; Gomez, R.A.; Chevalier, R.L.; Robillard, J.E. Neonatal renal function and physiology. Curr. Opin. Pediatr. 1994, 6, 172-177. [CrossRef]

14. Sulemanji, M.; Vakili, K. Neonatal renal physiology. Semin. Pediatr. Surg. 2013, 22, 195-198. [CrossRef] [PubMed]

15. Soullane, S.; Patel, S.; Claveau, M.; Wazneh, L.; Sant'Anna, G.; Beltempo, M. Fluid status in the first 10 days of life and death/bronchopulmonary dysplasia among preterm infants. Pediatr. Res. 2021, 90, 353-358. [CrossRef] [PubMed]

16. Agren, J.; Segar, J.L.; Soderstrom, F.; Bell, E.F. Fluid management considerations in extremely preterm infants born at 22-24 weeks of gestation. Semin. Perinatol. 2021, 46, 151541. [CrossRef] [PubMed]

17. Wada, M.; Kusuda, S.; Takahashi, N.; Nishida, H. Fluid and electrolyte balance in extremely preterm infants $<24$ weeks of gestation in the first week of life. Pediatr. Int. 2008, 50, 331-336. [CrossRef]

18. Monnikendam, C.S.; Mu, T.S.; Aden, J.K.; Lefkowitz, W.; Carr, N.R.; Aune, C.N.; Ahmad, K.A. Dysnatremia in extremely low birth weight infants is associated with multiple adverse outcomes. J. Perinatol. 2019, 39, 842-847. [CrossRef] [PubMed]

19. Gawlowski, Z.; Aladangady, N.; Coen, P.G. Hypernatraemia in preterm infants born at less than 27 weeks gestation. J. Paediatr. Child Health 2006, 42, 771-774. [CrossRef] [PubMed] 